\title{
El soft law en el contexto de las fuentes del derecho internacional: Aportes para la discusión
}

\author{
Soft law in light of the concept of sources of international law: \\ Contributing to the discussion
}

\author{
María Angélica Benavides Casals (iD \\ Universidad Central, Chile
}

\begin{abstract}
RESUMEN La teoría de las fuentes en derecho internacional público ha estado en discusión recientemente, tanto por el avance en sus áreas de manifestación como por los nuevos actores presentes en él, que han ido creando un cúmulo de instrumentos aglutinados bajo el concepto de soft law alegados por parte de la doctrina y la jurisprudencia como contenedores de obligaciones jurídicas. Esto hace necesario discutir sobre su naturaleza de fuente jurídica vinculante y su lugar en la teoría señalada, ya que es necesario evitar el forzar una nueva generación doctrinaria de fuente formal, que termine desvirtuando el consensualismo bajo el cual operan los Estados y que quite certeza a la protección que deben tener los individuos con respecto al actuar de estos.
\end{abstract}

PALABRAS CLAVE Soft law, fuentes del derecho internacional, derecho internacional contemporáneo, sociedad internacional, teoría de las fuentes.

ABSTRACT The theory of sources in public international law has been under discussion recently, both for its progress in its areas of manifestation and for the new actors present in it, who have been creating a cluster of instruments grouped under the concept of soft law, alleged by some doctrine and jurisprudence as containers of legal obligations. This makes it necessary to discuss its nature as a binding legal source and its place in the theory identified, since it is necessary to avoid forcing a new doctrinal generation of formal source, which ends up distorting the consensualism under which States operate and to remove certainty from the protection that individuals must have with regard to their State actions.

KEYWORDS Soft law, sources of international law, contemporary international law, international society, source theory. 


\section{Introducción}

El presente trabajo trata sobre los instrumentos denominados soft law. Pretende, por un lado, entregar al ámbito doctrinario elementos para discutir cómo esos instrumentos, derivados de distintas manifestaciones, se integran al sistema tradicional de fuentes $y$, por otro, entregar al operador judicial —en especial nacional- elementos que le permitan distinguir cuándo y cómo un instrumento denominado soft law puede ayudar a la resolución de un asunto, sin desvirtuar el sistema de creación del derecho aceptado por los Estados. El trabajo se basa en dos supuestos que se desarrollan. Uno, el acto soberano de los Estados de definir las normas jurídicas internacionales del derecho internacional público a las que se vinculan. Dos, que los instrumentos denominados soft law son de diversa naturaleza, origen, destinatario, etcétera, siendo imposible categorizarlos de forma unívoca. Su categorización o uso en el marco de la aplicación del derecho internacional público depende de cada instrumento. Ellos son de la más diversa naturaleza: resoluciones de órganos internacionales, recomendaciones de órganos especializados, resoluciones de instancias fiscalizadoras, etcétera.

Es así como este trabajo parte de la premisa de que el soft law, en el actual marco de las fuentes internacionales, no goza de la categoría de fuente formal y, por tanto, no genera la existencia de una obligación jurídica.

El trabajo parte con una caracterización de la sociedad internacional que impregna necesariamente el derecho internacional que la regula. Luego, se analiza aquello que identifica a una fuente formal. Posteriormente, se aborda si los instrumentos consignados como soft law tienen elementos comunes de que participen y puedan ser considerados todos bajo una misma categoría. Finalmente, se concluye que lo anterior no es posible y se ofrece una opción de incorporación razonable en la teoría de las fuentes mediante el elemento de la buena fe y la interpretación.

\section{Fuentes en derecho internacional público}

El derecho internacional público es un derecho especialísimo (Stein y Von Buttler, 2016: 20 y ss.; Verdross y Simma, 1984: 33 y ss.) en su forma de creación, cumplimiento y exigibilidad. Es el reflejo de una muy compleja sociedad a la que regula. Desde la teoría de las relaciones internacionales, es posible entender esta particularidad sociológica (Barbé, 1987: 156; Del Arenal, 1989: 155; Dupuy, 1991: 421-422). ${ }^{1}$ El derecho es una manifestación de las sociedades que regula, sin embargo, puede empujar cambios y el derecho internacional público no es ajeno a esta realidad. ${ }^{2}$

La Segunda Guerra Mundial constituye un punto de inflexión en la estructura de la sociedad internacional. El tránsito a un grupo social que, por voluntad, pasó de un grupo de Estados autoproclamados soberanos absolutos hacia un grupo de Estados con

1. Incluso en autores realistas como los referenciados, la sociedad y su conformación estatocentrista es una realidad dinámica, sujeta a eventuales cambios.

2. En derecho nacional se aprecia en las nuevas leyes sobre no discriminación. 
intenciones de operar sobre la base de la inclusión universal, definiendo como esencial el principio de autodeterminación y la prohibición del uso de la fuerza en la solución de las controversias entre ellos es, sin lugar a duda, un punto que torció el desarrollo mundial. Esta autolimitación en los derechos soberanos se produjo por un peligro real para la supervivencia de los Estados. Sin embargo, esta situación da cuenta de una paradoja: la intención positiva de crear una sociedad universal y la disposición limitada a una vinculación jurídica universal (Döhring, 2004: 121; Wiegandt, 2011: 35-36). ${ }^{3}$

La igualdad soberana de los Estados se manifiesta especialmente en la autolimitación del uso de la fuerza y el principio de autodeterminación (Carta de las Naciones Unidas, 1945: artículo 1, inciso 2, y artículo 2, incisos 1 y 2; Carta de la Organización de Estados Americanos, 1948: artículos 1 y 3 ). ${ }^{4}$

Es así como, frente a la construcción de esta sociedad inclusiva, los Estados se definen como entidades políticas con igualdad soberana. Esta es una ficción jurídica atendida las grandes diferencias reales existentes entre ellos, sean económicas, culturales, históricas, geográficas, demográficas, religiosas, jurídicas, etcétera. Es esta igualdad la que estructura a la sociedad internacional con la inexistencia de poderes centrales legislativos, ejecutivos y judiciales (Obando Camino, 2008). Sin perjuicio de esto, la sociedad incluye, actualmente, a otros sujetos de derecho internacional que, con competencias delimitadas y definidas por los Estados, han ido expandiendo o han pretendido expandir los límites del derecho, sus fuentes y, en definitiva, la forma en que los Estados se relacionan y asumen los cambios que ellos han propiciado (Bothe, 2015: $237 \mathrm{y}$ ss.).

Concentrándonos en la igualdad soberana y el rol legislativo, es necesario referirse a dos puntos previos.

El primero es que los Estados han rechazado contumazmente la existencia de un órgano legislativo con competencias generales y vinculantes (Seidl-Hohenveldern y Loibl, 2015). La creación progresiva internacional de organizaciones, si bien se presenta como un avance, constituye una parcelación de competencias y, además, con limitadas funciones normativas de vinculación jurídica. Así, la Organización Mundial de la Salud ${ }^{5}$ o la Unesco, ${ }^{6}$ ambas organizaciones sectoriales, no poseen una compe-

3. Siguiendo a Döhring, una Constitución o norma fundamental que regule jurídicamente la sociedad al estilo nacional, expresando autoridades, procesos y normas jurídicas, no existe en la sociedad internacional. Lo que no obsta a que sea considerado un sistema internacional, con orden jurídico, como expresa Wiegandt.

4. Las normas referidas son claros ejemplos de la positivización de la igualdad soberana y autodeterminación.

5. La rige su Tratado Constitutivo de 1946 en vigencia desde 1948. En su artículo 2 se establecen las competencias, que indican, en el fondo, labores de promoción, coordinación y propuesta a los Estados. Es, por tanto, un organismo de coordinación, y no posee competencias legislativas de las que emanen normas jurídicas vinculantes.

6. Su Tratado Constitutivo se fecha en 1946. En sus artículos 2 y 4 se señalan las competencias, que la constituyen como una organización intergubernamental de cooperación sin funciones legislativas vinculantes jurídicamente. 
tencia legislativa vinculante (Hillgenberg, 1998: 100 y ss.; Seidl-Hohenveldern, 1995).7

Lo segundo, y que deriva de lo anterior, es un sistema de fuentes del derecho internacional que podemos consignar como dependiente de aceptación estatal de vinculación o consentimiento. Los Estados han procurado mantener este sistema sobre la base de ciertas fuentes, en las que está presente el consentimiento como forma de crear y validar la vinculación y, por ende, la obligatoriedad jurídica (Orrego Vicuña, 2004: 83 y ss.; Sánchez Rodríguez, 2003).

Las fuentes aceptadas mayoritariamente son tratados, costumbre, principios generales del derecho, las sentencias para los Estados involucrados en el juicio (Sanz y Folloni, 2017: 245 y ss.; Cárdenas Castañeda, 2013; 358; Estatuto de la Corte Internacional de Justicia, 1945: artículo 38), ${ }^{8}$ los actos jurídicos unilaterales y la creación jurídica emanada de las organizaciones internacionales dentro de sus competencias. En cada una de ellas está presente el consentimiento para crear la vinculación jurídica. El consenso debe estar manifestado de forma clara, llegar a una concreción o manifestación que lo haga visible al resto de los Estados (Schilling, 2005: 242-243).

El derecho convencional no reviste mayores problemas en este sentido, atendido el acto de ratificación (Convención de Viena sobre el Derecho de los Tratados, 1969: artículo 11). ${ }^{9}$

En cuanto al derecho consuetudinario, la manifestación de voluntad del Estado se refleja en el comportamiento que adopta (Sánchez Rodríguez, 2003: 82 y ss.; Orrego Vicuña, 2011: 181 y ss.; Ferrer Llorent, 2012: 6-7). Si bien es un punto discutido por alguna parte de la doctrina (Cárdenas Castañeda y Casallas Méndez, 2015: 104), es posible sostener que el consentimiento se manifiesta en la reiteración de actos, ya que el Estado ha "aceptado» que es una obligación (Benavides Casals, 2015: 146-147). ${ }^{10}$ Sí resulta oportuna la aseveración de que, en la costumbre, no hay lugar a adecuaciones normativas. Esto significa que la costumbre no acepta «modificaciones», como puede suceder en los tratados mediante las reservas.

En los actos unilaterales también está presente el consentimiento. La característica del Estado, como sujeto principal del derecho internacional público, permite que cree normas incluso sin que exista otro sujeto que intervenga en la creación de la obligación

7. El significado del soft law emanado de esas organizaciones depende del tratado constitutivo y la praxis posterior.

8. El artículo mencionado del Estatuto de la Corte Internacional de Justicia establece fuentes, pero la doctrina reconoce otras fuentes formales, como los actos jurídicos unilaterales que no se encuentran en él. Es un artículo, por tanto, referencial, y no agota las posibilidades de establecer un sistema de fuentes dinámico que cambie con el curso del tiempo.

9. Dice: «El consentimiento de un Estado en obligarse por un tratado podrá manifestarse mediante la firma, el canje de instrumentos que constituyan un tratado la ratificación, la aceptación, la aprobación o la adhesión, o en cualquier otra forma que se hubiere convenido». Asimismo, la posibilidad de constituir obligaciones para un tercer Estado está expresamente regulada en los artículos 34 y 35, debiendo mediar el consentimiento del Estado sobre el que pesa dicha obligación, de forma escrita.

10. Ver discusión al respecto en la obra referenciada. 
(Barsalou, 2007: 400 y ss.). En cuanto a los principios generales del derecho, por disposición del artículo 38 del Estatuto de la Corte Internacional de Justicia, son los reconocidos por las naciones. La existencia del reconocimiento, si bien no indica la naturaleza positivista o iusnaturalista de ellos (Novak Talavera, 1997: 110 y ss.), implica que se tendrán por tales en el tráfico internacional aquellos que reflejen un mínimo común de aceptación, es decir, sobre los que haya coincidencia (Monroy Cabra, 2005: 84).

En el caso de las sentencias y las obligaciones que de ella nacen, fundan su vinculación jurídica en el consentimiento entregado por el Estado al someterse a esa jurisdicción. Así, se genera una obligación jurídica exigible para el Estado.

\section{El soft law en la estructura de fuentes del derecho internacional público}

La figura del soft law ha sido controversial en el ámbito académico (Gruchalla-Wesierski, 1984: 44 y ss.; Baxter, 1980; Di Robilant, 2006). La cuestión es dilucidar si constituye derecho y, por tanto, vincula jurídicamente al Estado y su no observancia genera responsabilidad internacional, consecuencia propia de la violación de una norma.

Entonces, es necesario referirse a tres ámbitos: qué es lo que identifica a las fuentes del derecho para señalar que ellas poseen este carácter; si el soft law presenta elementos o características que permitan señalar que constituye una fuente formal; y entregar elementos a la discusión doctrinaria y a los actores judiciales.

\section{Lo propio de una fuente jurídica}

El derecho, y el internacional no escapa a ello, conoce de fuentes formales y de fuentes materiales. En derecho internacional público, las primeras son aquellas de las que nacen normas jurídicas vinculantes, de cuya inobservancia se deriva responsabilidad internacional. Las segundas están constituidas por elementos que pueden llegar a influir en la comprensión de las primeras o cristalizarse en una de ellas (Ipsen, 1999: 113).

Las fuentes formales obedecen a determinados procesos de creación. Cada vez que se habla de tratados, costumbre u otra fuente formal del derecho, lo que encontramos es una identificación previa de los elementos propios de una fuente formal; esto es, sujeto con capacidad para crear normas, contenido normativo en cuanto a obligaciones y derechos, y la consecuente responsabilidad internacional en caso de violación. Un tratado es tal, sea que se le denomine convención, pacto, protocolo, etcétera, atendido a sus requisitos formales (Sentencia de la Corte Internacional de Justicia Qatar con Bahréin del 1 de julio de 1994). ${ }^{11}$ En este caso, sujeto con capacidad para contratar, contenido normativo con respecto a obligaciones y derechos, y un acuerdo de voluntades (Convención de Viena sobre el Derecho de los Tratados, 1969: artículo 2.a; Verdross

11. Remitida a la resolución de las excepciones preliminares de competencias interpuestas por Bahréin en el denominado «Asunto de la delimitación marítima y de las demás cuestiones territoriales entre Qatar y Bahréin». 
y Simma, 1984: 433). ${ }^{12}$ Cada vez que hay referencia a una sentencia internacional, se hace en consideración a sus requisitos formales de creación. Esto es un acto estatal previo de sometimiento - expreso o tácito - a la jurisdicción del órgano, un instrumento que contiene las cuestiones de hecho, derecho y la resolución que se enmarca en las competencias atribuida al respectivo órgano jurisdiccional. Una vez que se está en presencia de esos elementos, se habla de sentencia o fallo, o la denominación que se le entregue en los documentos que establecen las competencias para su dictación. Lo mismo ocurre con la costumbre. Se habla de ella desde la existencia de sus elementos. Una situación que contenga los elementos de opinio iuris y consuetudo permite referirse a esa realidad como una costumbre jurídica internacional (Sentencia de la Corte Internacional de Justicia Nicaragua con Estados Unidos del 27 de junio de 1986). ${ }^{13}$ Es decir, existe una referencia, explícita o implícita, al making law del derecho internacional público (Vitzhum, 2007: 76; Sentencia de la Corte Internacional de Justicia Alemania con Italia del 3 de febrero de 2012). ${ }^{14}$

Todo esto según la teoría tradicional de las fuentes, que nos entrega una clasificación de fuentes materiales y formales. La teoría de las fuentes ha sido estudiada y, tal como está, criticada por cierta parte de la doctrina (Sánchez Rodríguez, 2003; Meyer, 2009: 891). Esta crítica viene particularmente del esquema dinámico de fuentes y del constructivismo. El problema de la discusión radica en la estructura de la sociedad internacional y el derecho que la regula. Atendido que no existe un órgano legislativo central y vinculante para todos los Estados, es necesario que la discusión sobre el soft law se enmarque en la clasificación que los Estados, como principales sujetos del derecho internacional público, aceptan.

Dentro de la nomenclatura de soft law se aglutinan diversos instrumentos internacionales (Shelton, 2008: 3 y ss.), como documentos, observaciones, opiniones, declaraciones, etcétera. ${ }^{15}$

12. El artículo referenciado señala que se entiende por «tratado» un acuerdo internacional celebrado por escrito entre Estados y regido por el derecho internacional, ya sea que conste en un instrumento único o en dos o más instrumentos conexos y cualquiera que sea su denominación particular.

13. Relativa al denominado "Asunto actividades militares y paramilitares en y contra Nicaragua».

14. Ambos elementos son considerados necesarios para la existencia de una costumbre internacional. Ahora bien, en doctrina, se discute si la opinio iuris - elemento interno que revela un convencimiento jurídico para actuar- y el consuetudo - práctica estatal - son elementos constitutivos o declarativos de la costumbre. Para una exposición de la discusión, véase la referencia realizada a Vitzthum. Sin embargo, la idea del consentimiento y el consensualismo en la costumbre aparece reafirmada en jurisprudencia internacional reiterada, observando no solo el comportamiento internacional del Estado, sino también sus actos internos, sean judiciales, legislativos o de administración. Así, por ejemplo, en el caso de las inmunidades jurisdiccionales del Estado, tratado en la controversia entre Alemania e Italia: en ella, la Corte Internacional de Justicia, aportando elementos a la discusión al considerar el comportamiento como prueba de ambos elementos constitutivos de la costumbre, reafirma el carácter consensual del derecho internacional público.

15. Entre ellos: Resoluciones de la Asamblea General de la ONU, recomendaciones de comités de fiscalización de tratados, observaciones generales de comités especializados, etcétera. 
Todos ellos son instrumentos internacionales - como se les denomina en este trabajo- con disímiles características: órganos que los emiten, funciones dentro del sistema internacional, etcétera. Entonces, la pregunta es qué tendrían en común todos esos instrumentos que los harían partícipes de la naturaleza jurídica de una fuente formal llamada soft law.

Döhring (2004: 125) señala que el término ha sido creado para significar un espacio dudoso y de normatividad dudosa, que se encuentra «um ein Stadium zwischen Recht, wünschbarem Recht und werdendem Recht $z$ u charakterisieren» ${ }^{16}$. Consignando que el peligro está en la posibilidad de tratar esas tres distintas realidades como capaces de generar responsabilidad internacional. Ipsen (1999: 250-251) indica, asimismo, que estas manifestaciones no constituyen fuente jurídica alguna y que considerarlas como tal puede tener trasfondos más bien políticos e ideológicos.

\section{El soft law y las propiedades de una fuente formal}

Hasta ahora, en el presente trabajo se ha señalado, en primer lugar, que la sociedad internacional es altamente compleja, lo que se basa en su heterogeneidad e igualdad soberana. En segundo lugar, las fuentes formales tradicionalmente aceptadas derivan del consentimiento expreso o tácito de los Estados. En tercer lugar, esas fuentes formales protegen la certeza jurídica de los Estados mediante la responsabilidad internacional (D’Amato, 2008: 27). Y, en cuarto lugar, que el soft law es una categoría discutida.

La falta de concepto unánime de soft law se ha intentado paliar mediante análisis lógicos y de inducción (Sanz y Folloni, 2017: 247 y ss.) de algunos instrumentos a los que se refiere normalmente la doctrina como soft law, para arribar a un intento de definición, abstrayendo la casuística de los instrumentos (Del Toro Huerta, 2006: 516 y 525).

Un intento por la categorización de derecho se ha desarrollado por parte de la teoría de los sistemas dinámicos complejos o constructive international law, a los que se refiere Tomuschat (Herdegen, 2006: 899 y ss.). Esto, como se señalaba, critica la teoría tradicional de las fuentes abriendo camino al soft law en esta discusión.

Desde la teoría de los sistemas complejos, se señala que el derecho construye realidad como si se tratara de un sujeto autónomo (Teubner, 1990). Para eso, se requeriría un tránsito del realismo hacia el constructivismo social que desemboca en el derecho como un «Recht als epistemisches Subjekt» (Teubner, 1990: 119). ${ }^{17}$ Si bien no comparto estas teorías porque desembocan en incerteza jurídica, es necesario reconocerles la ventaja de integrar distintas disciplinas, que permiten observaciones complejas del fenómeno jurídico. Sin perjuicio de ello, y para efectos de un análisis del derecho internacional público, la axiología entrega suficientes elementos para una observación

16. «Estadio intermedio entre derecho, derecho que es deseable que exista y lo que llegará a ser derecho» (traducción propia).

17. «Derecho como un sujeto epistemológico» (traducción propia). 
del derecho desde lo que es posible encontrar de común en la sociedad internacional (Fastenrath, 1993: 306 y ss.; Fassbender, 1998).

Desde fines de la Segunda Guerra Mundial, la sociedad internacional ha definido, desde valores comunes (paz y seguridad internacional), un cúmulo de instrumentos que lentamente han ido dando paso a un derecho más eficiente y efectivo, aunque aún precario en diversas áreas. Es así como de la Convención contra el Genocidio pasó, décadas después, a establecerse un tribunal penal internacional, con delitos, procedimientos y competencias claras. Todo esto bajo la premisa de un recorrido lleno de discusiones, declaraciones, recomendaciones, etcétera, que permitieron lentamente abrir el espacio para llegar a un acuerdo jurídico vinculante sobre la materia (Bothe, 2015: 238-239). Es así como los Estados aún no abandonan la existencia de actos inequívocos para la creación de normas, basadas en la igualdad soberana y la autodeterminación. Esta es la forma en que irían construyendo una sociedad internacional que dé respuestas a problemas de protección en ámbitos valóricos, que, mediante el derecho internacional público, se constituyen como ámbitos jurídicos. Esta postura permite, reiteramos, la certeza jurídica en un medio social como el internacional, definido desde la heterogeneidad y la multipolaridad (Sánchez Rodríguez, 2003). ${ }^{18}$

El «konstruktive Völkerrecht» (Herdegen, 2006: 900), ${ }^{19}$ que abre una nueva forma de plantear la teoría de las fuentes, se basa - entre varios factores- en las diversas realidades fictas que el mismo derecho internacional público conoce y que desafían la teoría tradicional del consenso y la estricta teoría de las fuentes. Estas realidades están presenten en las figuras jurídico-ficticias, por ejemplo, de la opinio iuris. Ella es, esencialmente, una abstracción de las prácticas o abstenciones estatales, a las que la teoría tradicional de las fuentes entrega la posibilidad de constituir una norma consuetudinaria jurídicamente vinculante (Ferrer Llorent, 2006).

El ánimo que impulsa a este trabajo es el de considerar todos los elementos posibles que hagan del sistema de fuentes un sistema lo suficientemente dinámico, actualizado y seguro para los Estados como principales sujetos del derecho internacional público. Siendo así, es posible recoger de las teorías de los sistemas dinámicos y constructivos el hecho de que esta sociedad se mueve sobre la base de valores compartidos. En la actualidad, hay una sociedad que, en lo formal, acepta la existencia de valores determinados, por los que los Estados están dispuestos a celebrar conferencias, acuerdos, recomendaciones, declaraciones, etcétera. Esas manifestaciones inequívocas impregnarían el actuar de los Estados en la sociedad internacional, recogiendo un ethos - sistema dinámico y constructivista - cuyo lugar en el sistema internacional debe ser definido.

La pretendida juridicidad del soft law abre la posibilidad de ahondar la complejidad del derecho internacional público y la vinculación efectiva de los Estados. La existencia de un grupo de normas jurídicas que ellos aprecian como inequívocamente vinculantes, permite la posibilidad de accionar en el caso de incumplimiento mediante los efec-

18. Ver como crítica al sistema tradicional.

19. «Derecho internacional constructivo» (traducción propia). 
tos de la responsabilidad internacional. El peligro de contornos difusos entre aquello que los Estados aceptan como norma exigible y aquello que es un deseo de derecho o inicio de formación de derecho, constituiría una distorsión en que todo puede ser oponible y, por tanto, jurídicamente exigible al Estado.

Sin embargo, descartar a priori dentro del sistema de las fuentes todos los instrumentos a los que se les aplica la denominación soft law no parece razonable. Esto, porque muchos de esos instrumentos son, o bien actos estatales en el seno de ciertos órganos o foros, o bien actos emanados de estructuras - de diversa naturaleza - creadas por los Estados.

La mayoría de los instrumentos de soft law dan cuenta de una aceptación por parte de los Estados. Aceptación que, si bien no está destinada a crear una norma jurídica, reflejan, empero, el acuerdo sobre aspectos determinados, de común preocupación sobre el tema.

Esta aceptación puede provenir de diversos caminos. Ejemplo de esto son las resoluciones de la Asamblea General de Naciones Unidas. Existe un cúmulo de dichas declaraciones donde los Estados, en su conjunto, han accedido a manifestarse positivamente con respecto a determinados temas. ${ }^{20} \mathrm{Si}$ bien en cada una de ellas no es posible identificar la totalidad de los elementos que son condición de existencia una fuente formal, vistos precedentemente, no deja de ser contundente y sólido el apoyo que - aun cuando político- han prestado los Estados al nacimiento de esas normas no vinculantes.

La doctrina ha intentado ubicar esas manifestaciones en los principios generales y en la costumbre. Como señalan Verdross y Simma (1984: 420), las manifestaciones que se engloban bajo el concepto de soft law constituyen un «prederecho» que puede cristalizar en una fuente formal.

Algunas de las manifestaciones de soft law son, por ejemplo, las recomendaciones de órganos convencionales, opiniones consultivas de tribunales internacionales y resoluciones de la Asamblea General. En relación con las resoluciones o recomendaciones de órganos convencionales de fiscalización, hay voces que consideran que ellas extra-

20. Resoluciones de la Asamblea General de las Naciones Unidas ES-10/14 del 18 de diciembre de 2003; 48/88 del 29 de diciembre de 1993; 3452 (XXX) del 9 de diciembre de 1975; 3314 (XXIX) del 14 de diciembre de 1974; 2625 (XXV) del 24 de octubre de 1970; 2131 (XX) del 21 de diciembre de 1965; 1653 (XVI) del 24 de noviembre de 1961; y 616A y 616B (VII) del 5 de diciembre de 1952. Estas resoluciones han sido escogidas atendido el consenso que existe sobre su importancia en el sistema internacional. En específico, se remiten respectivamente a los siguientes temas: «Sobre medidas israelíes ilegales en la Jerusalén oriental ocupada y el resto del territorio palestino ocupado»; «Sobre la situación en Bosnia y Herzegovina»; «Declaración sobre la protección de todas las personas contra la tortura y otros tratos o penas crueles, inhumanos o degradantes»; «Sobre definición de la agresión»; «Declaración sobre los principios de derecho internacional referentes a las relaciones de amistad y a la cooperación entre los Estados de conformidad con la Carta de las Naciones Unidas»; «Declaración sobre inadmisibilidad de la intervención en los asuntos internos de los Estados y protección de su independencia y soberanía»; «Declaración sobre la prohibición del uso de armas nucleares y termonucleares»; y «Sobre la cuestión del conflicto racial en África del Sur, resultante de la política de segregación racial (apartheid) del gobierno de la Unión Sudafricana». 
limitan las competencias si pretenden obligatoriedad jurídica, sumado a un reproche de sesgo político (Bódig, 2016: 69; Rodley, 2013: 639). Con las opiniones consultivas, hay cierta claridad doctrinaria de que ellas constituyen insumos de avance y desarrollo del derecho internacional público, pero no por sí mismas fuentes formales (Benavides Casals, 2015). Sin embargo, en las resoluciones de la Asamblea General hay elementos que no pueden ser ignorados y considerados como meras declaraciones de buenas intenciones.

Las manifestaciones expresadas en las resoluciones de la Asamblea General son, sin duda, un comportamiento acompañado de una convicción, pero sin que sea posible definirlas como fuente formal. Sin embargo, el contenido de esas declaraciones, sumado al subsecuente comportamiento de los Estados, da cuenta, al menos, de un ánimo. Si ese ánimo sumado al subsecuente comportamiento se reflejara en, por ejemplo, normas internas de los Estados o comportamientos reiterados cuyo origen es el contenido de la declaración, podría hablarse y estudiarse la posibilidad de que ese contenido haya cristalizado en una costumbre jurídica internacional. Así lo propone Vitzthum (2007: 12). Esas declaraciones de la Asamblea General podrían constituir prueba del posterior nacimiento de una costumbre. Indicio, como sostiene Bleicher (1969: 446), de una futura fuente formal. Son, por tanto, catalizadores del futuro desarrollo del derecho internacional público, donde la autoridad que emite la declaración (paradigmáticamente, la Asamblea General) goza de la voluntad de la comunidad internacional general, la cual es esencial en la futura cristalización de una costumbre (Herdegen, 2009: 106).

Es así como la Corte Internacional de Justicia ha señalado, en diversos fallos y opiniones consultivas, que las resoluciones de la Asamblea General, no cada una en particular ni todas de forma general, reflejan un convencimiento que cristaliza según el comportamiento posterior de los Estados en una nueva fuente formal del derecho. Esto, sin embargo, no lo señala como si las resoluciones en sí mismas fuesen una nueva categoría de fuente formal. Indica que estas cristalizan una fuente formal de aquellas que el derecho internacional público ya conoce en la teoría tradicional de las fuentes (Badilla, 2015: 231 y ss.). Es así como en el caso Nicaragua con Estados Unidos, la Corte señala que el contenido de la Declaración Sobre los Principios de Derecho Internacional Referentes a las Relaciones de Amistad y a la Cooperación entre los Estados de Conformidad con la Carta de las Naciones Unidas de la Asamblea General (Resolución de la Asamblea General de las Naciones Unidas 2625 (XXV) de 24 de octubre de 1970) constituye un indicio de opinio iuris, que consistiría en el núcleo de una costumbre internacional aplicable al caso y oponible a Estados Unidos (Sentencia de la Corte Internacional de Justicia Nicaragua con Estados Unidos del 27 de junio de 1986: párrafo 191 y ss.). Igualmente, y sobre la misma resolución de la Asamblea General, se pronunció la Corte Internacional de Justicia en el caso República Democrática del Congo con Uganda (Sentencia de la Corte Internacional de Justicia República Democrática del Congo con Uganda del 19 de diciembre de 2005: párrafo 42 y ss.), ${ }^{21}$ señalando la violación a una

21. Relativo a «Actividades armadas en el Territorio del Congo». 
costumbre, cuya opinio iuris del contenido de la obligación fue establecida por los Estados en la Resolución 2625. Es importante reiterar que la Corte no ha definido ni insinuado que la resolución aludida es, en sí, una fuente formal. Pero sí atiende, en primer lugar, a la autoridad (Verdross y Simma, 1984: 420) de que goza el órgano que la emite, así como al comportamiento favorable del contenido de la declaración por la mayoría de los Estados y al anterior y posterior comportamiento de los Estados que refleja el nacimiento o existencia de una costumbre internacional.

Por lo tanto, la primera utilidad de las manifestaciones de soft law es la de ser un eventual insumo para la creación posterior de una fuente formal.

Visto esto, es necesario referirse a otro ámbito en el que algunas de estas manifestaciones de soft law sirvan al desarrollo del derecho internacional público, es decir, al de la interpretación (Hillgenberg, 1998: 100). Conocido es que el derecho internacional público, particularmente el convencional, conoce reglas y criterios de interpretación. Sin embargo, es aceptado mayoritariamente por la doctrina que esas normas forman parte no solo del derecho convencional, sino además del derecho consuetudinario. Ciertas manifestaciones que se consideran expresión del soft law, como las recién mencionadas resoluciones de la Asamblea General, pueden ser vistas desde el prisma de la interpretación (Gruchalla-Wesierski, 1984: 64; Shelton, 2008: 13-14). La regla del artículo 31 de la Convención de Viena establece una regla general de interpretación, con tres elementos de análisis (teleológico, sistemático y gramatical) y un supuesto de comportamiento (buena fe). Parece indudable que, existiendo una declaración de la Asamblea General, emanada de un órgano si bien sin competencias legislativas, inequívocamente se reflejen contenidos que los Estados aceptan al menos como existentes y sobre los que tienen convicción de formar parte de un acervo - no jurídico- pero de relación, entre ellos, como norma de comportamiento. Esto reconduce al contenido del artículo 31 de la Convención de Viena, obligación a la vez consuetudinaria, por la que los Estados deben cumplir dentro de los márgenes de la buena fe sus obligaciones jurídicas (Gruchalla-Wesierski, 1984: 62 y ss.; Alston y Goodman, 2013: 834). Siendo así, al menos las declaraciones de la Asamblea General, que como se ha señalado reflejan una aceptación de existencia de parámetros de comportamiento como la aludida Resolución 2526, son criterios que deben guiar a los Estados en su comportamiento referido al cumplimiento de sus deberes jurídicos existentes.

Un aporte de los instrumentos de soft law es el de ser un elemento contextual en la estructura interpretativa del artículo 31. Dentro del contexto es posible traer, como un elemento más junto a otros, alguna manifestación denominada soft law. Sin embargo, el intérprete debe interpretar la norma mediante los tres métodos que establece el mencionado artículo: la norma debe ser analizada a la luz del elemento sistemático, teleológico y gramatical. El intérprete está obligado, por el artículo 31, a utilizar los tres métodos, no existiendo jerarquía entre ellos (Köck, 1998: 219). Esto significa que, por ejemplo, el operador nacional no puede definir que la comprensión de la norma estará dada por el resultado obtenido de la aplicación de uno u otro método del artículo 31. Sumado a eso, cada uno de esos métodos debe conducir a la misma comprensión de la 
norma interpretada. Es decir, el soft law no puede ser, bajo ningún concepto, el soporte único de una interpretación. Es solo un elemento dentro de un método a utilizar. Emplear únicamente el soft law para fundamentar el sentido de una norma, viola una obligación internacional. Esto es, la contenida en el artículo 31 de la Convención de Viena, que dispone la utilización de la regla compleja de tres métodos de interpretación.

\section{Reflexiones a modo de conclusión}

Como se ha dicho a lo largo de este trabajo, los Estados han mantenido una falta de disposición para generar nuevas formas de creación de fuentes jurídicas. Consideramos que esto no debe ser evaluado ni negativa ni positivamente. Como señala Vitzthum (2007: 76), «recht ist Recht, wenn es vom einem zur Rechtsetzung befügneten Organ als rechtlich geltend gesetzt wird». ${ }^{22}$ Una perspectiva pragmática como esa tiene ventajas. Como se señaló, los Estados no han acordado, y está quizás lejos de ser así, la existencia de una estructura legislativa mundial, como son los poderes nacionales. Sin embargo, han creado un derecho internacional público, donde se reconocen fuentes formales que, habiendo dado su consentimiento en obligarse por ellas, los vinculan jurídicamente. No se trata de forzar un desarrollo de las fuentes en contra de la voluntad de los Estados. Se trata, más bien, de utilizar coherentemente todas esas fuentes formales y otros instrumentos que, sin vincularlos jurídicamente, permiten interpretar y/o cristalizar el derecho internacional público. Es en este último marco donde se ubicaría el rol que le cabe al llamado soft law: cristaliza derecho (es un elemento que desemboca en una fuente de las reconocidas por los estados) o es un elemento de interpretación dentro de alguno de los tres métodos de interpretación.

Sin embargo, se requiere atender, en cada caso, qué instrumento al que se le da la nomenclatura de soft law tiene la calidad para trasuntar un acuerdo de comportamiento que pueda ser insumo para cristalizar en una fuente formal, o bien ser parte de los elementos de interpretación de una norma existente. No son lo mismo la opinión consultiva de un tribunal internacional (que tiene reconocida falta de vinculación, pero goza de autoridad con respecto a las resoluciones de la Asamblea General donde participan todos los Estados) que las declaraciones o recomendaciones de órganos convencionales sin competencia para dictar normas vinculantes. Su función tampoco puede ser la misma. Cada instrumento debe ser ponderado en su mérito para lograr una definición que ayude al operador del derecho a distinguir si es un instrumento que cristalizó una fuente o bien se enmarca en el elemento sistemático de interpretación, uno de los tres que deben ser atendidos por el intérprete según el artículo 31 de la Convención de Viena.

La existencia de la sociedad internacional no solo se apoya en el derecho que los Estados crean. Es también un entramado de comportamientos y normas, pero la forma de

22. «El derecho es derecho cuando es dictado como norma vigente por quien tiene competencias para ello» (traducción propia). 
creación del derecho aún no ha cambiado. Es por eso por lo que se demanda, por una parte, dejar de lado impulsos por forzar la teoría de las fuentes desde veredas ideológicas; recayendo sobre quienes invocan soft law una exhaustiva prueba y explicación del porqué una expresión de él es elemento de interpretación o cristaliza una fuente formal. Y, por otro lado, se demanda la aceptación, por parte de los Estados, de que sus actos se engarzan en una delicada y compleja interrelación que no solo depende de sus manifestaciones con fuentes formales, sino también demanda lo obvio, esto es, atender — de buena fesus conductas en el marco general de la sociedad internacional (Thürer, 2005: 310 y ss.).

\section{Referencias}

Alston, Philip y Ryan Goodman (2013). International human rights. Oxford: Oxford University Press.

BAdilla, Elvira (2015). El rol de las resoluciones de la Asamblea General de la Naciones Unidas en el proceso de creación del derecho internacional contemporáneo. Tesis para optar al grado de doctor en Derecho de la Pontificia Universidad Católica de Chile. Disponible en bit.ly/2SWqeJq.

BARBÉ, Esther (1987). «El papel del realismo en las relaciones internacionales (la teoría política internacional de Hans J. Morgenthau». Revista de Estudios Políticos, 57: 149176. Disponible en bit.ly/2TKfMFo.

BARSALOU, Olivier (2007). «Les actes unilatéraux étatiques en droit international public: Observations sur quelques incertitudes théoriques et pratiques». The Canadian Yearbook of International Law, 44 (1): 395-420. DOI: 10.1017/So069005800009061.

BAXTER, Richard (1980). "International Law in "Her Infinite Variety"». The International and Comparative Law Quarterly, 29 (4): 549-566.

Benavides Casals, María Angélica (2015). «El efecto erga omnes de las sentencias de la Corte Interamericana de Derechos Humanos». International Law: Revista Colombiana de Derecho Internacional, 27: 141-166. Disponible en bit.ly/3AyLTIE.

Bleicher, Samuel (1969): «The legal significance of re-citation of general assembly resolutions». The American Journal of International Law, 63 (3): 444-478. DOI: $10.2307 / 2198866$.

BóDIG, Mátyás (2016). «Soft law, doctrinal development and the general comments of the UN Committee on Economic, Social and Cultural Rights». En Stéphanie Lagoutte, Thomas Gammeltoft-Hansen y John Cerone (editores), Tracing the Roles of Soft Law in Human Rights. Oxford: Oxford University Press. DOI: 10.1093/acprof:0 so/9780198791409.003.0005.

Botнe, Michael (2015). «Will current international crisis result in structural shifts in international law». Recueils de la Société Internationale de Droit Pénal Militaire et de Droit de la Guerre, 20: 231-248.

Cárdenas Castañeda, Fabián Augusto (2013). "A call for rethinking the sources of international law: Soft law and the other side of the coin». Anuario Mexicano de Derecho Internacional, 13 (1): 355-403. Disponible en bit.ly/2V8kMUh. 
Cárdenas Castañeda, Fabián Augusto y Óscar Orlando Casallas Méndez (2015). «Una gran medida de "opinio juris” y práctica estatal al gusto: ¿La receta de la costumbre internacional contemporánea?». Anuario Colombiano de Derecho Internacional (ACDI), 8: 87-130. Disponible en bit.ly/3qS49IA.

D’Amato, Anthony (2008). "International soft law, hard law and coherence». Northwestern Public Law Research Paper, 8 (1): 322-353. DOI: 10.2139/ssrn.1103915.

Del Arenal, Celestino (1989). «La teoría de las relaciones internacionales hoy: Debates y paradigma». Revista Estudios Internacionales (Universidad de Chile), 86: 153182. Disponible en bit.ly/3xmyhiz.

Del Toro Huerta, Mauricio (2006). «El fenómeno del soft law y las nuevas perspectivas del derecho internacional». Anuario Mexicano de Derecho Internacional, 6 (1): 513-549. Disponible en bit.ly/2UnipwC.

Di Robilant, Anna (2006). "Genealogies of soft law». The American Journal of Comparative Law, 54 (3): 499-554. DOI: 10.1093/ajcl/54.3.499.

DöHring, Karl (2004). Völkerrecht. 2. ${ }^{a}$ ed. Heidelberg: C. F. Müller Verlag.

Dupuy, Pierre-Marie (1991). «Soft law and the International law of the environment». Michigan Journal of International Law, 12 (2): 420-457. Disponible en bit.ly/3qRNuEE.

FAsSBENDER, Bardo (1998). «The united nations charter as constitution of the international community». Columbia Journal of Transnational Law, 36 (3): 529-619. Disponible en bit.ly/3jOjg8P.

FASTENRATH, Ulrich (1993). «Relative normativity in International Law». European Journal of International Law, 4 (3): 305-340. DOI: 10.1093/oxfordjournals.ejil. a035832.

Ferrer Llorent, Jaume (2006). Consenso en el proceso de formación institucional de normas en el derecho internacional. Barcelona: Atelier Libros S.A.

- (2012). «La insoportable levedad del derecho internacional consuetudinario en la jurisprudencia de la Corte Internacional de Justicia: El caso de las inmunidades jurisdiccionales del Estado». Revista Electrónica de Estudios Internacionales, 24: 2-37. Disponible en bit.ly/3xn18SU.

Gruchalla-Wesierski, Tadeusz (1984). «A framework for understanding soft law». McGill Law Journal, 30 (1): 37-88. Disponible en bit.ly/3wmqVcC.

Herdegen, Matthias (2006). «Das 'konstruktive Völkerrecht' und seine Grenzen: Die Dynamik des Völkerrechts als Methodenfrage». En Pierre-Marie Dupuy (editor), Völkerrecht als Wertordnung, Common Values in International Law: Festschrift für Christian Tomuschat. Kehl, Estrasburgo y Arlington: Engel Verlag.

-. (2009). Völkerrecht. München: C.H. Beck Verlag.

Hillgenberg, Hartmut (1998): «Soft law im völkerrecht». Zeitschrift für Europarechtliche Studien ZEuS, 1: 81-102.

IpSEN, Knut (1999). Völkerrecht. $4 .^{\text {a }}$ ed. München: C.H. Beck Verlag.

KöcK, Heribert Franz (1998). Zur Interpretation völkerrechtlicher verträge. ZÖR, 53: 217-237. 
Meyer, Timothy (2009). «Soft law as delegation». Fordham International Law Journal, 32 (3): 888-942. Disponible en bit.ly/3xm5glT.

Monroy Cabra, Marco Gerardo (2005). «Aproximación al concepto de fuentes del derecho internacional». Estudios Socio-Jurídicos, 7 (2): 77-91. Disponible en bit. ly/3hjckdy.

Novak Talavera, Fabián (1997). «Los principios generales del derecho: La buena fe y el abuso del derecho». Revista Agenda Internacional (Pontificia Universidad Católica del Perú), 4 (9): 109-133. Disponible en bit.ly/3hEV951.

Оваndo Camino, Iván Mauricio (2008). «Anarquía internacional y derechos humanos». En Gonzalo Aguilar Cavallo (editor), 60 años después: Enseñanzas pasadas y desafíos futuros. Santiago: Librotecnia.

OrRego Vicuña, Francisco (2004). «Creación del derecho en una sociedad global: ¿Importa todavía el consentimiento?». Revista Estudios Internacionales (Universidad de Chile), 37 (146): 81-103. Disponible en bit.ly/2UsoB6u.

OrRego Vicuña, Francisco (2011). "Customary international law in action: From the international minimum standard to fair and equitable treatment». En Holger P. Hestermeyer, Doris König, Nele Matz-Luck, Volker Röben, Anja Seibert-Fohr, Peter-Tobias Stoll, Silja Vöneky (editores), Coexistence, cooperation and solidarity: Liber amicorum rüdiger wolfrum. Leiden: Martinus Nijhoff.

RodLey, Nigel (2013). «The role and impact of treaty bodies». En Dinah Shelton (editora), The oxford handbook of international human rights. Oxford: Oxford University Press.

SÁnchez Rodríguez, Luis (2003). «La apoteosis del consentimiento: De la noción de fuentes a los procesos de creación de derechos y obligaciones internacionales». Anuario Hispano-Luso-Americano de Derecho Internacional, 16 (1): 191-234.

SANZ, Rafael y André Folloni (2017). «El soft law como fuente del derecho internacional: Reflexiones desde la teoría de la complejidad». Revista de Direito Internacional, 14 (3): 243-259. Disponible en bit.ly/3ACfxfR.

Schilling, Theodor (2005). «Völkerkonsensrecht». En Jürgen Bröhmer, Roland Bieber, Christian Callies, Christine Langenfeld, Stefan Weber y Joachim Wolf (editores), Internationale Gemeinschaft und Menschenrechte: Festschrift für Georg Ress zum 7o. Geburtstag am 21. Januar 2005. Köln: Carl Heymann Verlag.

SeIdL-Hohenveldern, Ignaz (1995). «Internationale Organisationen aufgrund von soft law». En Rudolf Bernhardt y Ulrich Beyerlin (editores), Recht zwischen Umbruch und Bewahrung: Festschrift für Rudolf Bernhardt. Berlín: Springer Verlag.

Seidl-Hohenveldern, Ignaz y Gerhard Loibl (2015). Das recht der internationalen organisationen einschließlich der supranationalen gemeinschaften. . $^{\text {a }}$ ed. Köln: Carl Heymann Verlag.

Shelton, Dinah (2008). «Soft law». En David Armstrong (editor), Routledge handbook of international law. Abingdon y Nueva York: Routledge Press.

Stein, Torsten y Christian Von Buttler (2016). Völkerrecht. 16. ${ }^{\mathrm{a}}$ ed. Múnich: Vahlen. 
Teubner, Günther (1990). «Die episteme des rechts. Zu erkenntnistheoretischen grundlagen des reflexiven Rechts». En Dieter Grimm (editor), Wachsende Staatsaufgaben - sinkende Steuerungsfähigkeit des Rechts. Baden-Baden: Nomos.

Thürer, Daniel (2005). «Von der komplexen Gestalt des völkerrechts». En Jürgen Bröhmer, Roland Bieber, Christian Callies, Christine Langenfeld, Stefan Weber y Joachim Wolf (editores), Internationale Gemeinschaft und Menschenrechte: Festschrift für Georg Ress zum 70. Geburtstag am 21. Januar 2005. Köln: Carl Heymann Verlag.

Verdross, Alfred y Bruno Simma (1984). Universelles Völkerrecht: Theorie und Praxis. 3. ${ }^{\text {a }}$ ed. Berlín: Duncker \& Humblot.

Vitzthum, Wolfgang (2007). Völkerrecht. 4. ${ }^{\mathrm{a}}$ ed. Berlín: De Gruyter Recht.

WiEgANDT, Jan (2011). «Internationale rechtsordnung oder machtordnung? Eine anmerkung zum verhältnis von macht und recht im völkerrecht». Zeitschrift für ausländisches öffentliches recht und völkerrecht ZaöRV, 71 (1): 31-76. Disponible en bit. ly/3jSjBmi.

\section{Sobre la autora}

María Angélica Benavides Casals es licenciada en Derecho por la Pontificia Universidad Católica de Chile, doctora y LL.M. Eur. por la Universidad del Sarre, Alemania. Actualmente, es profesora de Derecho Internacional Público de la Universidad Central de Santiago de Chile. (D) https://orcid.org/00o 0-0001-7174-8751. 
La Revista de Derecho Público es publicada desde 1963 por el Departamento de Derecho Público de la Facultad de Derecho de la Universidad de Chile. Aparece dos veces al año. Su propósito es la difusión de los avances del derecho público nacional e internacional y la socialización de artículos de investigación inéditos de la comunidad académica nacional e internacional.

DIRECTORA

Ana María García Barzelatto

SECRETARIO DE REDACCIÓN

Felipe Peroti Díaz

fperoti@derecho.uchile.cl

SITIO WEB

revistaderechopublico.uchile.cl

CORREO ELECTRÓNICO

publico@derecho.uchile.cl

LICENCIA DE ESTE ARTÍCULO

Creative Commons Atribución Compartir Igual 4.o Internacional

La edición de textos, el diseño editorial

y la conversión a formatos electrónicos de este artículo

estuvieron a cargo de Tipográfica

www.tipografica.io 